\title{
A Long Non-Coding RNA snaR Contributes to 5-Fluorouracil Resistance in Human Colon Cancer Cells
}

\author{
Heejin Lee ${ }^{1}$, Chongtae $\mathrm{Kim}^{1}$, Ja-Lok $\mathrm{Ku}^{2}$, Wook Kim ${ }^{3}$, Sungjoo Kim Yoon ${ }^{4,5}$, Hyo-Jeong Kuh ${ }^{4,5}$, \\ Jeong-Hwa Lee ${ }^{1,4}$, Suk Woo Nam ${ }^{4,6}$, and Eun Kyung Lee ${ }^{1,4, *}$
}

\begin{abstract}
Several types of genetic and epigenetic regulation have been implicated in the development of drug resistance, one significant challenge for cancer therapy. Although changes in the expression of non-coding RNA are also responsible for drug resistance, the specific identities and roles of them remain to be elucidated. Long non-coding RNAs (IncRNAs) are a type of ncRNA (> $200 \mathrm{nt}$ ) that influence the regulation of gene expression in various ways. In this study, we aimed to identify differentially expressed IncRNAs in 5-fluorouracil-resistant colon cancer cells. Using two pairs of 5-FU-resistant cells derived from the human colon cancer cell lines SNU-C4 and SNU-C5, we analyzed the expression of 90 IncRNAs by qPCR-based profiling and found that 19 and 23 IncRNAs were differentially expressed in SNU-C4R and SNU-C5R cells, respectively. We confirmed that snaR and BACE1AS were downregulated in resistant cells. To further investigate the effects of snaR on cell growth, cell viability and cell cycle were analyzed after transfection of siRNAs targeting snaR. Down-regulation of snaR decreased cell death after 5-FU treatment, which indicates that snaR loss decreases in vitro sensitivity to 5 -FU. Our results provide an important insight into the involvement of IncRNAs in 5-FU resistance in colon cancer cells.
\end{abstract}

\section{INTRODUCTION}

Drug resistance is considered a multifactorial phenomenon that

\begin{abstract}
${ }^{1}$ Department of Biochemistry, College of Medicine, Catholic University of Korea, Seoul 137-701, Korea, ${ }^{2}$ Cancer Research Institute and Cancer Research Center, Seoul National University, Seoul 110-744, Korea, ${ }^{3}$ Department of Molecular Science and Technology, Ajou University, Suwon 443-749, Korea, ${ }^{4}$ Cancer Evolution Research Center, ${ }^{5}$ Department of Biomedical Science, ${ }^{6}$ Department of Pathology, College of Medicine, Catholic University of Korea, Seoul 137-701, Korea

*Correspondence: leeek@ catholic.ac.kr
\end{abstract}

Received 5 June, 2014; revised 30 June, 2014; accepted 30 June, 2014; published online 31 July, 2014

Keywords: 5-Fluorouracil, cell viability, drug resistance, long non-coding RNAs, snaR results from a variety of factors, including individual variations in patients and genetic and/or epigenetic differences in tumors (Raguz and Yague, 2008; Tan et al., 2010). Although chemotherapy has been widely used for cancer treatment, acquisition of drug resistance is considered a substantial obstacle in effective chemotherapy (Kang et al., 2013). Altered expression or mutation of transporter proteins that increase drug efflux from cancer cells, reduce uptake of drugs, increase repair of DNA damage, decrease sensitivity resulting from induction of apoptosis, and accelerate drug metabolism are responsible for the development of drug resistance (Fojo, 2007; Glasspool et al., 2006; Roberti et al., 2006; Tan et al., 2010). Recently, several studies have shown that non-mutational regulation of gene expression by microRNAs (miRNAs) is also largely involved in the acquisition of drug resistance (Fojo, 2007; Mishra, 2012; Mishra and Bertino, 2009; Xu et al., 2013).

5-Fluorouracil (5-FU), a classical anti-metabolite, is widely used for cancer treatment and results in cytotoxic effects that cause cell death by affecting nucleoside metabolism [International Multicentre Polled Analysis of Colon Cancer Trials (IMPACT) investigators, 1995; Grem, 2000; Zhang et al., 2008]. However, clinical applications of 5-FU have been limited by drug resistance (Peters et al., 2002; Zhang et al., 2008). Although several efforts have been made to elucidate the molecular events causing the 5-FU-resistant phenotype, no convincing findings have been reported with regard to simple gene expression changes (Boyer et al., 2006; Karasawa et al., 2009; Kurokawa et al., 2012; Mariadason et al., 2003; Ooyama et al., 2006). Therefore, multiple and distinct factors may be related to primary or acquired 5-FU resistance.

Genome-wide studies have revealed that different types of non-coding RNAs (ncRNAs) regulate gene expression (Djebali et al., 2012; Taft et al., 2010). Small ncRNAs such as siRNAs, miRNAs, and piRNAs are highly conserved and engage in transcriptional and posttranscriptional gene silencing by interacting with their targets. Long non-coding RNAs (IncRNAs) have a length greater than $200 \mathrm{nt}$, are poorly conserved, and belong to a novel heterogeneous class of ncRNAs that includes thousands of different species (Mercer et al., 2009; Whitehead et al., 2009; Wilusz et al., 2009). IncRNAs are emerging as new players in gene regulation that affect various stages of gene expression through diverse mechanisms that have not yet been fully elucidated (Batista and Chang, 2013; Rinn and Chang, 

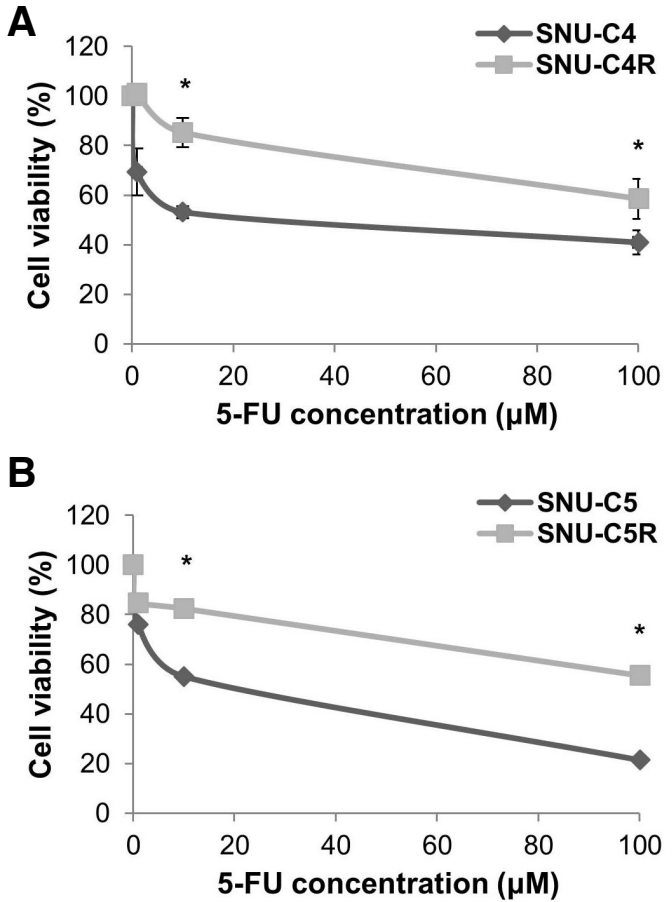

Fig. 1. Chemosensitivity of 5-FU-resistant human colon cancer cells, SNU-C4R and SNU-C5R. Human colon cancer cells (SNU-C4 and SNU-C5) and their 5-FU-resistant cells (SNU-C4R and SNU-C5R) were exposed to the indicated concentration of 5-FU. After $72 \mathrm{~h}$, cell viability was assessed by MTT assay. (A) SNU-C4 vs. SNUC4R, (B) SNU-C5 vs. SNU-C5R. Data represent the mean \pm SEM from 3 independent experiments. ${ }^{*} p<0.05$.

2012). Several studies have indicated that the expression of IncRNAs is tightly controlled with regard to cell and tissue distribution, and aberrant expression is involved in development and diseases, including cancers (Esteller, 2011; Fatica and Bozzoni, 2013; Gibb et al., 2011; Wang and Chang, 2011). However, the functional link between IncRNAs and the acquisition of drug resistance is unclear.

In this study, we explored the altered expression of IncRNAs in two different 5-FU-resistant human colon cancer cell lines and further investigated the role of snaR, which is a downregulated IncRNA in 5-FU-resistant cells. Our results provide experimental evidence that differential expression of IncRNAs such as snaR is responsible for altered chemosensitivity to 5FU and provide a possible link between IncRNAs and 5-FU resistance.

\section{MATERIALS AND METHODS}

Cell culture and transfection

The human colon cancer cell lines SNU-C4 and SNU-C5 (Oh et al., 1999; Park et al., 1987), and their individual 5-FU-resistant cell lines, SNU-C4R and SNU-C5R, were obtained from the Korean Cell Line Bank (Korea) (Choi et al., 2011; Shin et al., 2005; 2009). SNU-C4, SNU-C5, and HCT-116 cells were maintained in RPMI medium (Thermo Scientific Inc.) supplemented with $10 \%$ fetal bovine serum and $1 \%$ penicillin/streptomycin. Resistant cells were maintained in RPMI $10 \% \mathrm{FBS} / 1 \%$ penicillin/streptomycin and exposed to $I_{50}$ value to 5 -FU (Sigma) for 72 h. siRNAs (siCTRL, 5'-AAUUCUCCGAACGUGUCACGU-
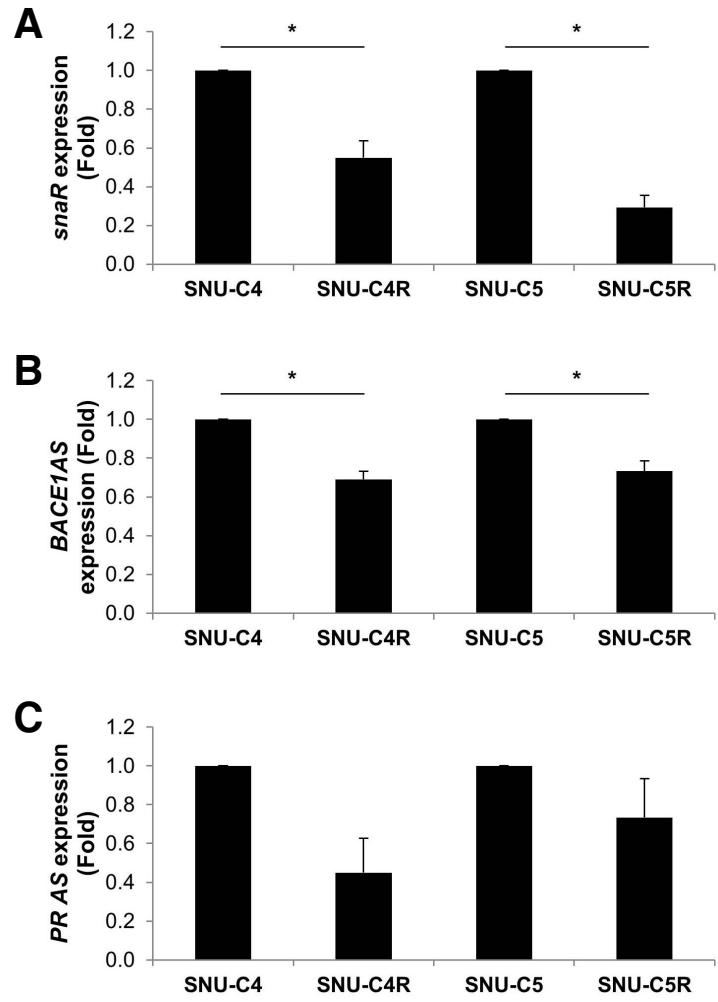

Fig. 2. Validation of differentially expressed IncRNAs in 5-FUresistant cells. Total RNAs were isolated from 5-FU-resistant cell lines (SNU-C4R and SNU-C5R) and their parental cells (SNU-C4 and SNU-C5), and CDNAs were synthesized by reverse transcripttion. Relative expression of (A) snaR, (B) BACE1AS, and (C) PRAS among cell lines was analyzed by RT-qPCR. Data represent the mean \pm SEM from 3 independent experiments. ${ }^{*} p<0.05$.

3'; and sisnaR, 5'-CCACAUGGGUCGGAAAAAAUU-3') were synthesized (Genolution, Korea) and transfected using Lipofectamine 2000 (Life Technologies).

MTT assay

A colorimetric assay using the tetrazolium salt, 3-(4,5-dimethylthiazol-2-yl)-2,5-diphenyltetrazolium bromide (MTT), was used to assess cell viability. After $24 \mathrm{~h}$ of transfection with siRNA, cells were exposed to $10 \mu \mathrm{M} 5$-FU for $72 \mathrm{~h}$. Additionally, 0.5 $\mathrm{mg} / \mathrm{mL}$ of MTT was added to each well and incubated for $3 \mathrm{~h}$. Plates were centrifuged at $450 \times g$ for $5 \mathrm{~min}$ at room temperature, the medium was removed, and then $100 \mu \mathrm{l}$ of $40 \mathrm{mM}$ acidic isopropanol was added to solubilize the crystals. The absorbance was measured at $570 \mathrm{~mm}$ using a microplate reader, Victor 3 (Perkin Elmer, Finland).

RNA analysis and RT-qPCR

Total RNA was prepared from whole cells by using TRIzol reagent (Invitrogen). After reverse transcription (RT) using random hexamers and reverse transcriptase (Toyobo, Japan), the abundance of transcripts was assessed by quantitative PCR (qPCR) analysis by using SYBR green PCR master mix (Kapa Biosystems) and the following gene-specific primer sets: snaR_Fwd: 5'-TGGAGCCATTGTGGCTCCGGCC-3', snaR Rev: 5'-CCCATGTGGACCAGGTTGGCCT-3'; PRAS Fwd: 5'GCCTCGGGTTGTAGATTTCA-3', PRAS_Rev: 5'-AGGTCC 
Down-Regulation of snaR Is Responsible for 5-FU Resistance

Heejin Lee et al.

Table 1. Differentially expressed IncRNAs in SNU-C4R cells

\begin{tabular}{lcc}
\hline NCBI Reference sequence & IncRNAs & Expression in SNU-C4R/SNU-C4 \\
\hline N/A & PRAS & 0.20 \\
NR_002819.2 & Malat1 & 0.34 \\
N/A & NTT & 0.44 \\
NR_003245.1 & HAR1B & 0.48 \\
N/A & DHFR upstream transcripts & 0.49 \\
NR_002795.2 & Hoxa11as & 0.51 \\
NR_002578.2 & GAS5-family & 0.53 \\
NR_004435.1 & snaR & 0.53 \\
NR_004428.1 & EGO B & 0.54 \\
NR_002196.1 & H19 & 0.59 \\
NR_002770.1 & Dio3os & 0.62 \\
N/A & E2F4 antisense & 0.63 \\
NR_047514.1 & Air & 0.66 \\
NR_037803.1 & BACE1AS (family) & 0.66 \\
NR_023917.1 & PTENP1 & 0.64 \\
N/A & TEA ncRNAs & 0.64 \\
NR_001568.1 & BC200 & 2.38 \\
NR_015391.1 & LOC285194 & 2.12 \\
NR_023388.1 & PRINS & 2.10 \\
\hline
\end{tabular}

$\mathrm{N} / \mathrm{A}, \mathrm{NCBI}$ reference sequence information is not available.

A

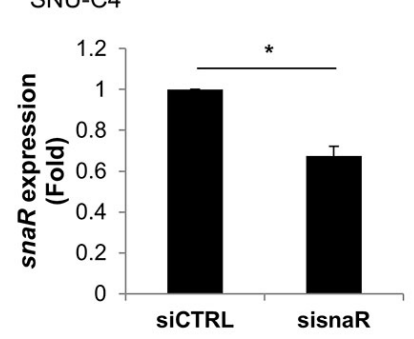

B

$$
\text { SNU-C5 }
$$

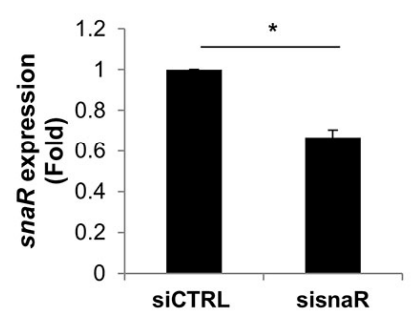

C ${ }_{\text {HCT-116 }}$

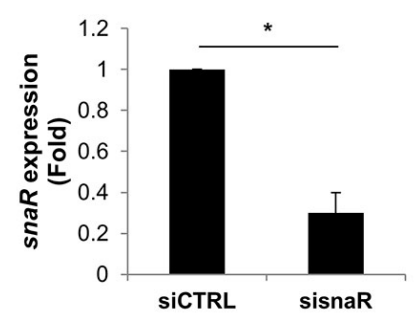

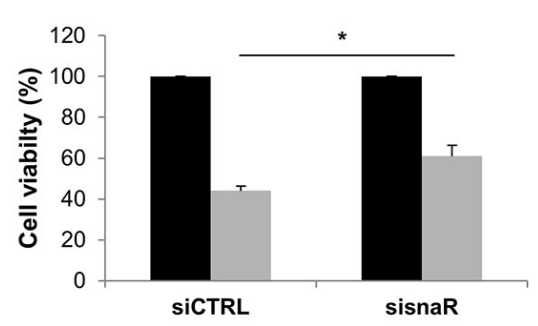

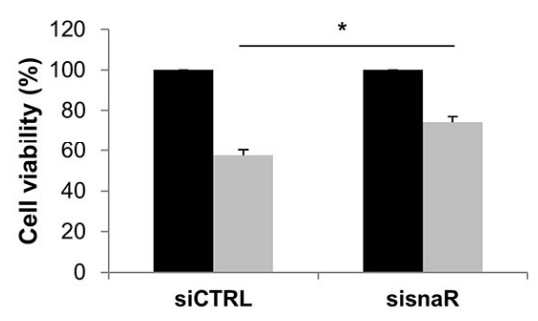

- un-teated

5-FU $10 \mu \mathrm{M}$

- un-treated 5-FU $10 \mu \mathrm{M}$

(C) HCT-116 cells was measured by RTqPCR. GAPDH mRNA was used as an internal control. After transfection of siRNAs, cells were exposed to $10 \mu \mathrm{M} 5$-FU for $72 \mathrm{~h}$ and cell viability was assessed by MTT assay (A, right) SNU-C4, ( $\mathrm{B}$, right) $\mathrm{SNU}-\mathrm{C} 5$ or $(\mathrm{C}$, right) HCT-116 cells. Data represent the mean \pm SEM from 3 independent experiments. ${ }^{*} p<0.05$. 
Table 2. Differentially expressed IncRNAs in SNU-C5R cells

\begin{tabular}{|c|c|c|}
\hline NCBI Reference sequence & IncRNAs & Expression in SNU-C5R/SNU-C5 \\
\hline NR_003529.3 & ANRIL & 0.42 \\
\hline NR_004435.1 & snaR & 0.47 \\
\hline NR_024582.1 & Jpx & 0.55 \\
\hline NR_002791.2 & Emx2os & 0.60 \\
\hline $\mathrm{N} / \mathrm{A}$ & lincRNA-VLDLR & 0.61 \\
\hline NR_003141.3 & SNHG4 & 0.61 \\
\hline $\mathrm{N} / \mathrm{A}$ & HULC & 0.62 \\
\hline NR_002323.1 & TUG1 (family) & 0.63 \\
\hline NR_024281 & RNCR3 & 0.64 \\
\hline NR_015391.1 & LOC285194 & 0.65 \\
\hline NR_002795.2 & Hoxa11as & 0.65 \\
\hline NR_015379.3 & UCA1 & 0.66 \\
\hline NR_037803.1 & BACE1AS (family) & 0.83 \\
\hline $\mathrm{N} / \mathrm{A}$ & Evf1 and EVF2 & 3.04 \\
\hline NR_004428.1 & EGO B & 2.77 \\
\hline $\mathrm{N} / \mathrm{A}$ & PRAS & 2.40 \\
\hline $\mathrm{N} / \mathrm{A}$ & E2F4 antisense & 1.96 \\
\hline $\mathrm{N} / \mathrm{A}$ & lincRNA-p21 & 1.91 \\
\hline NR_002196.1 & $\mathrm{H} 19$ & 1.64 \\
\hline $\mathrm{N} / \mathrm{A}$ & L1PA16 & 1.58 \\
\hline $\mathrm{N} / \mathrm{A}$ & IPW & 1.56 \\
\hline NR_023920 & WT1-AS & 1.54 \\
\hline NR_002578.2 & GAS5-family & 1.52 \\
\hline
\end{tabular}

$\mathrm{N} / \mathrm{A}, \mathrm{NCBI}$ reference sequence information is not available.

GGTAATTGGGGTAG-3'; BACE1AS_Fwd: 5'-ATTTCACCCT GTTGGTCAGG-3', BACE1AS_Rev: 5'-TCAGCAACAGCCA AGATGTC-3'; GAPDH_Fwd: 5'-TGCACCACCAACTGCTTA GC-3', GAPDH_Rev: 5'-GGCATGGACTGTGGTCATGAG-3'. RT-qPCR analysis was performed using a StepOne Plus ${ }^{\mathrm{TM}}$ instrument (Life Technologies). GAPDH mRNA was used as the internal control for normalization. The relative expression of transcripts was analyzed using the $2^{-\Lambda \Lambda} \mathrm{Ct}$ method.

\section{Flow cytometric analysis}

The cell cycle was evaluated by fluorescence-activated cellsorting (FACS) analysis of propidium iodide-stained nuclei as previously described (Fulda et al., 1998). After transfection of siRNA and/or 5-FU treatment, cells were stained with propidium iodide (Sigma), and the cell cycle was analyzed by flow cytometry (FACSCalibur). Cell death was determined by staining Annexin V using Aposcan kit (Biobud, Korea) according to the manufacturers' protocol.

\section{IncRNA profiling}

IncRNA profiling was performed using IncRNA profiler ${ }^{\mathrm{TM}} \mathrm{qPCR}$ arrays (System Bioscience, Inc., USA) consisting of 90 IncRNAs. Total RNA was isolated from each cell line by using TRIzol reagent (Invitrogen). cDNAs for IncRNA profiling were synthesized by reverse transcription after polyadenylation and annealing of oligo-dTs, and RT-qPCR reaction was performed according to the manufacturer's protocol.

\section{RESULTS}

Chemosensitivity of SNU-C4R and SNU-C5R cells to 5-FU Two 5-FU-resistant SNU-C4R and SNU-C5R cell lines were previously established from human colon cancer cells, SNU-C4 and SNU-C5, respectively (Choi et al., 2011; Jung et al., 2007; Shin et al., 2005; 2009). We confirmed the relative chemosensitivity of these resistant cell lines against 5-FU using MTT assay. 5-FU treatment for $72 \mathrm{~h}$ resulted in a dose-dependent suppression of cell growth (Fig. 1). The $I_{50}$ values for 5-FU in SNUC4R and SNU-C5R cells were $105.0 \pm 14.5 \mu \mathrm{M}$ and $118.7 \pm$ $4.9 \mu \mathrm{M}$, respectively, and the corresponding values for their parental cells, SNU-C4 and SNU-C5 cells were $8.3 \pm 4.7 \mu \mathrm{M}$ and $23.2 \pm 3.4 \mu \mathrm{M}$, respectively.

Differential expression of IncRNAs in 5-FU-resistant cells To explore the potential role of long non-coding RNAs (IncRNAs) in 5-FU resistance, we investigated the differential expression of IncRNAs between 5-FU-resistant cells and their parental cells by performing qPCR-based IncRNA profiling according to the manufacturer's protocol (System Bioscience, Inc.). We analyzed the relative expression of 90 IncRNAs and observed differential expression of IncRNAs in the 5-FU-resistant cell lines. In all, in SNU-C4R and SNU-C5R cells, 16 and 12 IncRNAs were down-regulated by more than 1.5-fold, whereas 3 and 10 IncRNAs were up-regulated by more than 1.5-fold, respectively (Tables 1 and 2). These results suggest that these IncRNAs may play roles in the development of 5-FU 
A

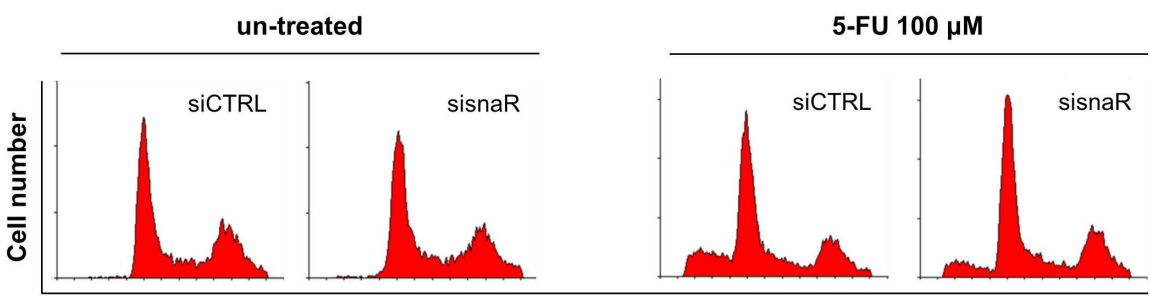

B
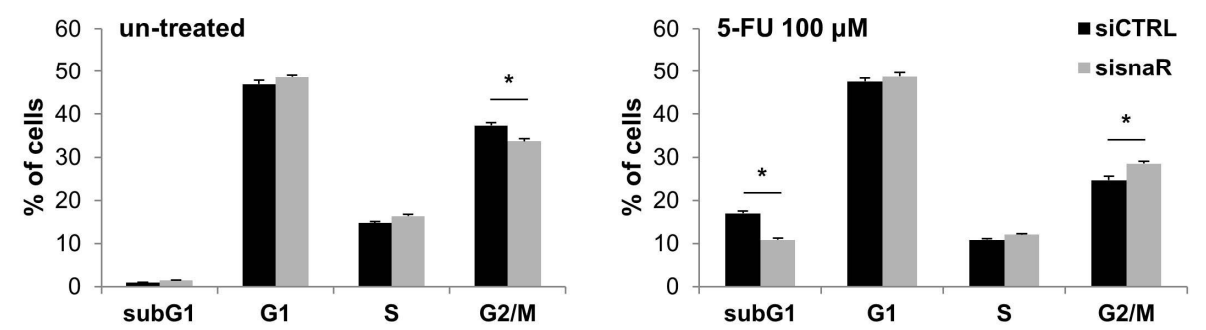

Fig. 4. Down-regulation of snaR decreases cell death after 5-FU treatment. After transfection of siRNA targeting snaR or control siRNA, HCT-116 cells were exposed to $100 \mu \mathrm{M} 5-\mathrm{FU}$ for $16 \mathrm{~h}$. (A and $B)$ Cells were stained with propidium iodide and the distribution of cell cycles between untreated (left) and 5-FU-treated (right) cells were analyzed by flow cytometry. The cytograms are representative of three independent experiments. (C) For measure of apoptotic cells, the cells were stained with both propidium iodide and Annexin $\mathrm{V}$ and analyzed by flow cytometry. The results represent the mean \pm SEM from 3 independent experiments. ${ }^{*} p<0.05$.

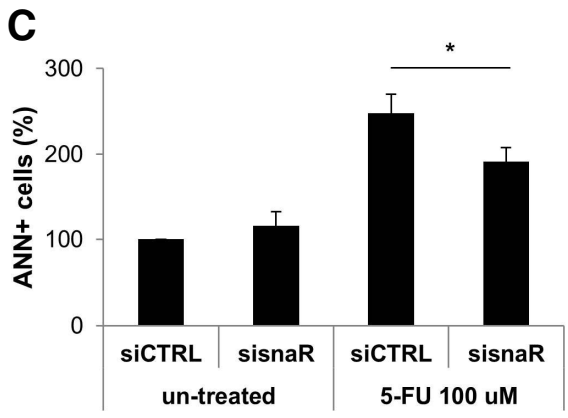

resistance in human colon cancer cells.

Validation of array data by RT-qPCR

To validate the results from the profiling analysis, we selected three IncRNAs, snaR, BACE1AS, and PRAS, and we detected their expression by RT-qPCR using specific primer sets. SnaR and BACE1AS were significantly down-regulated in both resistant cell lines (SNU-C4R and SNU-C5R), whereas PRAS was down-regulated in SNU-C4R cells but not in SNU-C5R cells (Fig. 2). These results indicate that the expression of the three IncRNAs assessed by RT-qPCR was consistent with the IncRNA profiling analysis shown in Tables 1 and 2. From these results, we hypothesized that differential expression of IncRNAs may have functions in the 5-FU resistance in colon cancer cells.

\section{Effect of snaR on cell growth after 5-FU treatment}

To explore whether the differentially expressed IncRNAs are involved in the regulation of 5-FU responsiveness, we further examined the effect of snaR, which was down-regulated in both 5-FU-resistant cell lines, on cell growth. Because resistant cells showed down-regulation of snaR, we hypothesized that the loss of snaR is responsible for the increase in cell viability after 5-FU treatment. To validate this hypothesis, we investigated the effect of snaR down-regulation on cell viability after 5-FU treatment. Small interfering RNA against snaR was synthesized and transfected into SNU-C4, SNU-C5 and HCT-116 cells, and snaR expression level was then analyzed by RT-qPCR. Trans- fection of siRNA targeting snaR significantly down-regulated snaR expression in each cell lines (Figs. 3A, 3B, and 3C, left). After transfections of sisnaR or siCTRL, cells were exposed to 5-FU for $72 \mathrm{~h}$, and then cell viability was assessed by MTT assay. Down-regulation of snaR resulted in increased cell viability after 5-FU treatment (Figs. 3A, 3B and 3C, right). To further investigate the effect of snaR on cell cycle regulation, the cell cycle distribution and cell death were analyzed by flow cytometry (Fig. 4). snaR down-regulation did not produce significant changes in cell cycle distribution at the baseline (Figs. 4A and $4 \mathrm{~B}$, left); however, it resulted in a significant decrease of sub-G1 phase of the cell cycle after 5-FU treatment (Figs. 4A and $4 \mathrm{~B}$, right). Additionally, snaR down-regulation decreased Annexin V-positive (ANN+) apoptotic cells after 5-FU treatment (Fig. 4C). These results indicate that loss of snaR, which was observed in 5-FU-resistant cells, is responsible for the development of 5-FU resistance in colon cancer cells.

\section{DISCUSSION}

Anti-cancer drug resistance remains one of the most significant challenges to successful treatment of cancer (Gottesman, 2002). Although the mechanism of drug resistance has not been fully elucidated, many studies have revealed that genetic alterations of several genes encoding membrane transporters, drug metabolizers, and cell cycle regulators, and those involved in the DNA repair process are responsible for the development 
of drug resistance (Ganguly et al., 2011). In addition, numerous studies have also indicated the involvement of substantial epigenetic regulation by DNA methylation or miRNAs in drug resistance (Ma et al., 2010; Rukov and Shomron, 2011; Strathdee, 2007; Wang et al., 2010; Zheng et al., 2010).

In addition to miRNAs, IncRNAs also participate in a wide spectrum of biological processes through diverse mechanisms that affect transcription, mRNA splicing, mRNA decay, translation, and protein-protein interaction (Batista and Chang, 2013; Gibb et al., 2011; Wang and Chang, 2011). Recent studies have shown that IncRNAs such as HOTAIR and UCA1 contribute to cisplatin resistance (Fan et al., 2014; Liu et al., 2013). However, IncRNA expression in drug resistance and its physiopathological significance have not yet been fully elucidated.

Here, we hypothesized that treatment of an anti-cancer drug, 5-FU, may be associated with the alteration of IncRNAs profiles. Therefore, we investigated differentially expressed IncRNAs in two 5-FU-resistant human colon cancer cell lines. We found that several IncRNAs such as snaR, BACE1AS, and PRAS were differentially expressed in 5-FU-resistant cells. Although both resistant cells showed chemoresistance to 5-FU, there was little correlation in the expression of IncRNAs, which might be resulted from the different genetic background of their parental cells (Oh et al., 1999; Park et al., 1987). Our results suggested that the differential expression of these IncRNAs is involved in the development of 5-FU resistance in human colon cancer cells. Furthermore, the potential role of snaR in the regulation of $5-\mathrm{FU}$ responsiveness was implicated. SnaR is an IncRNA ( 117 nt) transcribed by RNA polymerase III that associates with nuclear factor 90 (NF90; a double-stranded RNAbinding protein implicated in multiple cellular functions) (Parrott and Mathews, 2007). Several snaR transcripts have been found in diverse cell lines and human tissues, and they associate with ribosomes in the cytoplasm (Parrott and Mathews, 2009; Parrott et al., 2011). Although previous reports suggest that snaR transcripts are involved in tissue- and speciesspecific regulation of cell growth and translation, the detailed functions of snaR have not yet been elucidated.

In this study, we found that snaR was down-regulated in 5FU-resistant colon cancer cells, and snaR loss increased cell viability after 5-FU treatment, which suggests that snaR has a potential role as a negative regulator of cell growth in response to 5-FU. Further experiments will be necessary to obtain more information regarding the roles of snaR in 5-FU resistance. We believe that our results may be useful as a starting point for further studies to elucidate the molecular functions of IncRNAs in drug resistance and to assess their therapeutic potentials.

\section{ACKNOWLEDGMENTS}

This work is supported by the National Research Foundation of Korea (NRF) grant funded by the Korea government [Ministry of Education, Science and Technology (MEST)] (2012M3A9 D105451, 2012R1A5A2047939).

\section{REFERENCES}

Batista, P.J., and Chang, H.Y. (2013). Long noncoding RNAs: cellular address codes in development and disease. Cell 152, 12981307.

Boyer, J., Allen, W.L., McLean, E.G., Wilson, P.M., McCulla, A., Moore, S., Longley, D.B., Caldas, C., and Johnston, P.G. (2006) Pharmacogenomic identification of novel determinants of response to chemotherapy in colon cancer. Cancer Res. 66, 2765-2777.

Choi, C.H., Lee, T.B., Lee, Y.A., Choi, S., and Kim, K.J. (2011). Upregulation of cyclooxygenase-2-derived prostaglandin $\mathrm{E}(2)$ in co-
Ion cancer cells resistant to 5 -fluorouracil. J. Korean Surg. Soc. 81, 115-121.

Djebali, S., Davis, C.A., Merkel, A., Dobin, A., Lassmann, T., Mortazavi, A., Tanzer, A., Lagarde, J., Lin, W., Schlesinger, F., et al. (2012). Landscape of transcription in human cells. Nature 489 , 101-108.

Esteller, M. (2011). Non-coding RNAs in human disease. Nat. Rev. Genet. 12, 861-874.

Fan, Y., Shen, B., Tan, M., Mu, X., Qin, Y., Zhang, F., and Liu, Y. (2014). Long non-coding RNA UCA1 increases chemoresistances of bladder cancer cells by regulating Wnt signaling. FEBS J. 281, 1750-1758

Fatica, A., and Bozzoni, I. (2013). Long non-coding RNAs: new players in cell differentiation and development. Nat. Rev. Genet. 15, 7-21

Fojo, T. (2007). Multiple paths to a drug resistance phenotype: mutations, translocations, deletions and amplification of coding genes or promoter regions, epigenetic changes and microRNAs. Drug Resist. Updat. 10, 59-67.

Fulda, S., Susin, S.A., Kroemer, G., and Debatin, K.M. (1998). Molecular ordering of apoptosis induced by anticancer drugs in neuroblastoma cells. Cancer Res. 58, 4453-4460.

Ganguly, A., Banerjee, K., Chakraborty, P., Das, S., Sarkar, A., Hazra, A., Banerjee, M., Maity, A., Chatterjee, M., Mondal, N.B., et al. (2011). Overcoming multidrug resistance (MDR) in cancer in vitro and in vivo by a quinoline derivative. Biomed. Pharmacother. 65, 387-394.

Gibb, E.A., Brown, C.J., and Lam, W.L. (2011). The functional role of long non-coding RNA in human carcinomas. Mol. Cancer 10 38.

Glasspool, R.M., Teodoridis, J.M., and Brown, R. (2006). Epigenetics as a mechanism driving polygenic clinical drug resistance. $\mathrm{Br}$. J. Cancer 94, 1087-1092.

Gottesman, M.M. (2002). Mechanisms of cancer drug resistance. Ann. Rev. Med. 53, 615-627.

Grem, J.L. (2000). 5-Fluorouracil: forty-plus and still ticking. A review of its preclinical and clinical development. Invest. New Drugs 18, 299-313.

International Multicentre Pooled Analysis of Colon Cancer Trials (IMPACT) investigators (1995). Efficacy of adjuvant fluorouracil and folinic acid in colon cancer. Lancet 345, 939-944.

Jung, G.R., Kim, K.J., Choi, C.H., Lee, T.B., Han, S.I., Han, H.K., and Lim, S.C. (2007). Effect of betulinic acid on anticancer drug resistant colon cancer cells. Basic Clin. Pharmacol. Toxicol. 101, 277-285.

Kang, H., Kim, C., Lee, H., Kim, W., and Lee, E.K. (2013). Posttranscriptional controls by ribonucleoprotein complexes in the acquisition of drug resistance. Int. J. Mol. Sci. 14, 17204-17220.

Karasawa, H., Miura, K., Fujibuchi, W., Ishida, K., Kaneko, N., Kinouchi, M., Okabe, M., Ando, T., Murata, Y., Sasaki, H., et al. (2009). Down-regulation of clAP2 enhances 5-FU sensitivity through the apoptotic pathway in human colon cancer cells. Cancer Sci. 100, 903-913.

Kurokawa, K., Tanahashi, T., lima, T., Yamamoto, Y., Akaike, Y., Nishida, K., Masuda, K., Kuwano, Y., Murakami, Y., Fukushima, M., et al. (2012). Role of miR-19b and its target mRNAs in 5fluorouracil resistance in colon cancer cells. J. Gastroenterol. 47, 883-895.

Liu, Z., Sun, M., Lu, K., Liu, J., Zhang, M., Wu, W., De, W., Wang $Z$., and Wang, R. (2013). The long noncoding RNA HOTAIR contributes to cisplatin resistance of human lung adenocarcinoma cells via downregualtion of $\mathrm{p} 21(\mathrm{WAF} 1 / \mathrm{CIP} 1)$ expression. PLoS One 8, e 77293.

Ma, J., Dong, C., and Ji, C. (2010). MicroRNA and drug resistance. Cancer Gene Ther. 17, 523-531.

Mariadason, J.M., Arango, D., Shi, Q., Wilson, A.J., Corner, G.A., Nicholas, C., Aranes, M.J., Lesser, M., Schwartz, E.L., and Augenlicht, L.H. (2003). Gene expression profiling-based prediction of response of colon carcinoma cells to 5-fluorouracil and camptothecin. Cancer Res. 63, 8791-8812.

Mercer, T.R., Dinger, M.E., and Mattick, J.S. (2009). Long noncoding RNAs: insights into functions. Nat. Rev. Genet. 10, 155159.

Mishra, P.J. (2012). The miRNA-drug resistance connection: a new era of personalized medicine using noncoding RNA begins. Pharmacogenomics 13, 1321-1324. 
Mishra, P.J., and Bertino, J.R. (2009). MicroRNA polymorphisms: the future of pharmacogenomics, molecular epidemiology and individualized medicine. Pharmacogenomics 10, 399-416.

Oh, J.H., Ku, J.L., Yoon, K.A., Kwon, H.J., Kim, W.H., Park, H.S., Yeo, K.S., Song, S.Y., Chung, J.K., and Park, J.G. (1999). Establishment and characterization of 12 human colorectal-carcinoma cell lines. International journal of cancer. J. Int. Cancer 81, 902-910.

Ooyama, A., Takechi, T., Toda, E., Nagase, H., Okayama, Y., Kitazato, K., Sugimoto, Y., Oka, T., and Fukushima, M. (2006). Gene expression analysis using human cancer xenografts to identify novel predictive marker genes for the efficacy of 5fluorouracil-based drugs. Cancer Sci. 97, 510-522.

Park, J.G., Oie, H.K., Sugarbaker, P.H., Henslee, J.G., Chen, T.R., Johnson, B.E., and Gazdar, A. (1987). Characteristics of cell lines established from human colorectal carcinoma. Cancer Res. 47, 6710-6718.

Parrott, A.M., and Mathews, M.B. (2007). Novel rapidly evolving hominid RNAs bind nuclear factor 90 and display tissue-restricted distribution. Nucleic Acids Res. 35, 6249-6258.

Parrott, A.M., and Mathews, M.B. (2009). snaR genes: recent descendants of Alu involved in the evolution of chorionic gonadotropins. Cold Spring Harbor Symp. Quant. Biol. 74, 363-373.

Parrott, A.M., Tsai, M., Batchu, P., Ryan, K., Ozer, H.L., Tian, B. and Mathews, M.B. (2011). The evolution and expression of the snaR family of small non-coding RNAs. Nucleic Acids Res. 39, 1485-1500.

Peters, G.J., Backus, H.H., Freemantle, S., van Triest, B., CodacciPisanelli, G., van der Wilt, C.L., Smid, K., Lunec, J., Calvert, A.H., Marsh, S., et al. (2002). Induction of thymidylate synthase as a 5 -fluorouracil resistance mechanism. Biochim. Biophys. Acta 1587, 194-205.

Raguz, S., and Yague, E. (2008). Resistance to chemotherapy: new treatments and novel insights into an old problem. Br. J. Cancer 99, 387-391.

Rinn, J.L., and Chang, H.Y. (2012). Genome regulation by long noncoding RNAs. Ann. Rev. Biochem. 81, 145-166.

Roberti, A., La Sala, D., and Cinti, C. (2006). Multiple genetic and epigenetic interacting mechanisms contribute to clonally selection of drug-resistant tumors: current views and new therapeutic prospective. J. Cell. Physiol. 207, 571-581.
Rukov, J.L., and Shomron, N. (2011). MicroRNA pharmacogenomics: post-transcriptional regulation of drug response. Trends Mol. Med. 17, 412-423.

Shin, Y.K., Yoo, B.C., Chang, H.J., Jeon, E., Hong, S.H., Jung, M.S., Lim, S.J., and Park, J.G. (2005). Down-regulation of mitochondrial F1F0-ATP synthase in human colon cancer cells with induced 5-fluorouracil resistance. Cancer Res. 65, 3162-3170.

Shin, Y.K., Yoo, B.C., Hong, Y.S., Chang, H.J., Jung, K.H., Jeong, S.Y., and Park, J.G. (2009). Upregulation of glycolytic enzymes in proteins secreted from human colon cancer cells with 5fluorouracil resistance. Electrophoresis 30, 2182-2192.

Strathdee, G. (2007). Epigenetic markers and response to chemotherapy in cancer. Dis. Markers 23, 43-49.

Taft, R.J., Pang, K.C., Mercer, T.R., Dinger, M., and Mattick, J.S. (2010). Non-coding RNAs: regulators of disease. J. Pathol. 220, 126-139.

Tan, D.S., Gerlinger, M., Teh, B.T., and Swanton, C. (2010). Anticancer drug resistance: understanding the mechanisms through the use of integrative genomics and functional RNA interference. Eur. J. Cancer 46, 2166-2177.

Wang, K.C., and Chang, H.Y. (2011). Molecular mechanisms of long noncoding RNAs. Mol. Cell 43, 904-914.

Wang, Z., Li, Y., Ahmad, A., Azmi, A.S., Kong, D., Banerjee, S., and Sarkar, F.H. (2010). Targeting miRNAs involved in cancer stem cell and EMT regulation: an emerging concept in overcoming drug resistance. Drug Resist. Updat. 13, 109-118.

Whitehead, J., Pandey, G.K., and Kanduri, C. (2009). Regulation of the mammalian epigenome by long noncoding RNAs. Biochim. Biophys. Acta 1790, 936-947.

Wilusz, J.E., Sunwoo, H., and Spector, D.L. (2009). Long noncoding RNAs: functional surprises from the RNA world. Genes Dev. 23, 1494-1504.

Xu, X., Chen, H., Lin, Y., Hu, Z., Mao, Y., Wu, J., Xu, X., Zhu, Y., Li, S., Zheng, X., et al. (2013). MicroRNA-409-3p inhibits migration and invasion of bladder cancer cells via targeting c-Met. Mol. Cells 36, 62-68.

Zhang, N., Yin, Y., Xu, S.J., and Chen, W.S. (2008). 5-Fluorouracil: mechanisms of resistance and reversal strategies. Molecules 13 1551-1569.

Zheng, T., Wang, J., Chen, X., and Liu, L. (2010). Role of microRNA in anticancer drug resistance. Int. J. Cancer 126, 2-10. 